\title{
Fundamental Study on Assessment of Soil Erosion by the USLE Method at Rehabilitation Area in Indonesian Coal Mine
}

\author{
Naoya Inoue ${ }^{1}$, Akihiro Hamanaka ${ }^{1}$, Hideki Shimada ${ }^{1}$, Takashi Sasaoka ${ }^{1} \&$ Kikuo Matsui ${ }^{1}$ \\ ${ }^{1}$ Department of Earth Resources Engineeering, Faculty of Engineering, Kyusyu University, Japan \\ Correspondence: Naoya Inoue, Department of Earth Resources Engineeering, Faculty of Engineering, Kyusyu \\ University, Fukuoka, Japan. Tel: 81-92-802-3334. E-mail: n_inoue12r@mine.kyushu-u.ac.jp
}

Received: November 7, 2014 Accepted: December 4, 2014 Online Published: January 10, 2015

doi:10.5539/esr.v4n1p61 URL: http://dx.doi.org/10.5539/esr.v4n1p61

\begin{abstract}
Mining operation of open cut mines gives serious impacts on the surrounding environments. Therefore, an appropriate rehabilitation program has to be taken into consideration. Soil erosion is one of the major environmental problems in open cut mines in tropical regions. The soil erosion leads to unsuccessful rehabilitation due to topsoil losses. In order to succeed rehabilitation, the condition of soil erosion in the rehabilitation area has to be predicted accurately. As one of an efficient method for prediction of soil loss, Universal Soil Loss Equation (USLE) is the most widely used method of predicting soil loss in forestry. However, when considering the application of this equation in rehabilitation area, a sufficient consideration is needed because the condition of these areas is very different from that of forestry. This paper describes the reliability to predict soil erosion in rehabilitation area by means of USLE, and discusses the several considerations on soil erosion.
\end{abstract}

Keywords: open cut mine, Indonesia, soil erosion, Universal Soil Loss Equation

\section{Introduction}

Japan imports almost of coal resources from abroad countries. Indonesia is the second largest coal exporter to Japan and open cut mining is applied to produce coal resources, mainly. As the demand of coal not only in Indonesia but also in the rest of the world is increased dramatically due to increasing the energy supply in the world, the development of coal mining is advanced in order to meet the demand of coal. However, a mining operation of open cut mines gives serious impacts on surrounding environment. Therefore, in order to prevent and minimize the impact for environment, rehabilitation of the post mine surface should be conducted as soon after the surface mining operation has finished.

Among the impacts on environment, soil erosion is one of significant problems in the post mine surface. Indonesia belongs to tropical rainforest climates and soil erosion is easy to accelerate under the high rainfall level, especially in sharp cloudbursts such as squall. From this reason, severe erosion phenomena such as gully erosion, surface erosion, raindrop erosion and rill erosion and soil degradation are likely to occur in Indonesian surface mining (Jha \& Kapat, 2009). This situation leads to the unsuccessful rehabilitation in the post mine surface. Therefore, the degree of soil erosion in the rehabilitation area has to be assessed adequately and some countermeasures have to be taken in order to monitor and/or manage rehabilitation area in the long term.

As one of an efficient method for predicting the soil loss by rainfall, the Universal Soil Loss Equation (USLE), as modified for forestland by Dissmeyer and Foster (1984), is the most widely used method of predicting soil loss in forestry (Hood et al., 2002). The USLE is simple, easy to use, and require numerous input parameters or extensive data sets for prediction. However, when considering the application of this equation in the rehabilitation area, a sufficient consideration is needed because the condition of the area is quite different from that of forestry. From these reasons, the estimation of soil erosion by means of USLE and artificial rainfall experiment in a laboratory were carried out in order to assess soil erosion in advance.

\section{Method}

\subsection{Universal Soil Loss Equation (USLE)}

The USLE is derived from a large database based on many years of data from plot experiments in the United States. This equation is the most widely used the empirical model worldwide for estimating soil loss. It 
calculates mean annual soil loss as a product of five factors (Wischmeier \& Smith, 1978).

$$
A=R * K * L S * C * P
$$

Note. $\mathrm{A}=$ average annual soil loss (tons/ha/year); $\mathrm{R}=$ rainfall and runoff factor $(\mathrm{MJ} \mathrm{mm} \mathrm{ha} / \mathrm{h} / \mathrm{year}$ ); $\mathrm{K}=$ soil erodibility factor (ton ha $\mathrm{h} / \mathrm{ha} / \mathrm{MJ} / \mathrm{mm}$ ); $\mathrm{LS}=$ slope and length of slope factor; $\mathrm{C}=$ cropping-management factor; $\mathrm{P}=$ supporting/conservation practice factor

2.1.1 Rainfall and runoff factor: $\mathrm{R}$

$\mathrm{R}$ represents the effort energy and intensity of rainfall. This factor is showed as following (Wischmeier \& Smith, 1978).

$$
\begin{gathered}
R=E I \\
E=916+331 \log _{10} I
\end{gathered}
$$

Note. $\mathrm{E}=$ Energy in the rainfall $(\mathrm{MJ} / \mathrm{ha}) ; \mathrm{I}=$ Maximum rainfall intensity of the rain $(\mathrm{mm} / \mathrm{h})$

To apply the USLE model, $\mathrm{R}$ factor can be calculated related on available data. Monthly rainfall, daily rainfall and yearly rainfall are treated to calculate $\mathrm{R}$ value.

\subsubsection{Soil Erodibility Factor: K}

The soil erodibility factor $(\mathrm{K})$ represents the susceptibility of a soil type to erosion. $\mathrm{K}$ is decided as following equation in this study (Wischmeier \& Smith, 1978).

$$
K=2.1 M 1.14\left(10^{-6}\right)(12-a)+0.0325(b-2)+0.025(c-3)
$$

Note. $\mathrm{M}=(\%$ silt $+\%$ very fine sand $)(100-\%$ clay $) ; \mathrm{a}=$ The percent organic matter content; $\mathrm{b}=$ Soil structure code; $\mathrm{c}=$ Soil permeability rating code

The $\mathrm{b}$ and $\mathrm{c}$ values is defined as based on a lot of experimental data under the various type of soil. Usually, value for $\mathrm{K}$ factor ranges from 0 to 0.7 in metric units, and high-clay content soil indicates the lower $\mathrm{K}$ factor values and high-sand and high-silt content soils indicates the higher values (Goldman et al., 1986).

\subsubsection{Slope and Length of Slope Factor: LS}

The length and slope steepness factor (LS) represents the effect of topography on erosion. LS factor can be described as (5) equation (Haan et al. 1994).

$$
L S=(\lambda / 22.14)^{m}\left(65.41 \sin ^{2} \theta+4.65 \sin \theta+0.065\right)
$$

Note. $\lambda=$ Slope length $(\mathrm{m}) ; \theta=$ Slope angle (degree); $\mathrm{m}=0.2$ for gradients less than $1 \%, 0.3$ for 1 to $3 \%$ slopes, 0.4 for 3.5 to $4.5 \%$ slopes, and 0.5 for slopes of $5 \%$ and greater.

\subsubsection{Cropping Management Factor: C}

Cropping management factor is defined as the ratio of soil loss from land with specific vegetation to the corresponding soil loss from clean tilled, continuous fallow. When the soil surface is bare, $\mathrm{C}$ is 1.0 and $\mathrm{C}$ factor value of 0.1 is used if a complete cover of newly seeded annual grasses is well established before the onset of rains (Goldman et al., 1986).

\subsubsection{Supporting/Conservation Practice Factor: $\mathrm{P}$}

$\mathrm{P}$ factor is defined as the ratio of soil loss with a given surface condition to soil loss with the cultivation method. Supporting conservation practices in the field reduces the velocity of runoff and the tendency of runoff which flow directly down a slope. When there are no supporting practices in the target area, this factor is 1.0 (Wischmeier \& Smith, 1978).

In this study, as the bare ground in the rehabilitation area of Indonesian coal mine is assumed as the target area, the USLE for predicting the soil loss is dealt as equation (6).

$$
A=R * K * L S
$$

\subsection{Artificial Rainfall Experiment}

In order to discuss the soil erosion under the various conditions, a laboratory study was conducted in order to predict total soil loss under various soil conditions by using an artificial rainfall simulator, which was prepared in our laboratory. The advantages of this experiment are to evaluate soil erosion for a short period and flexibility for arranging topography and soil texture (Commandeur, 1992). The soil loss of soil sample from the artificial rainfall was measured in this experiment. The equipment used is shown in Figure 1. Rainfall was simulated by drops of water free falling, starting at zero velocity, from protruding needles with an internal diameter of 0.80 
mm (Dimoyiannis et al., 2001). A certain amount of rainfall which was arranged by changing the pressure head by adjusting the water flow into the rainfall simulator gave the soil samples within the allotted amount of time. The duration of every experiment was 30 minutes. A soil sample was set on a rectangular shaped bed sizing 311 x 103 x $50 \mathrm{~mm}$. The slope of soil bed was changed by the pulley. In this experiment, various amount of rainfall gave the soil samples in the predetermined time under the various soil composition and topographic condition.

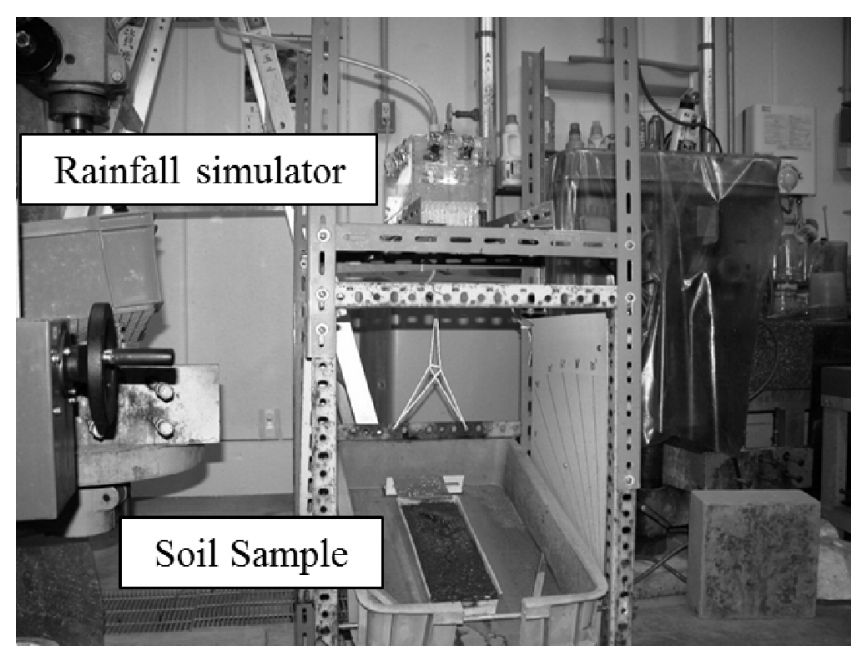

Figure 1. Artificial rainfall equipment

\section{Results and Discussions}

\subsection{Soil Sample}

At first, field research was conducted in order to investigate the soil composition and topographic condition in the rehabilitation area (Lembak Block) of Kaltim Prima Coal mine. In addition, soil samples were prepared in the same distribution of grain size and $15 \%$ of water content as with field condition and artificial rainfall experiment was carried out (see Table 1). After that, in order to investigate the effect for soil loss by the difference of soil grain size, the performance of soil runoff and the characteristics of the individual soil sample (sand, silt and clay) were discussed.

Table 1. Soil samples

\begin{tabular}{ccccc}
\hline Sample & Sand $(\%)$ & Silt $(\%)$ & Clay $(\%)$ & Slope degree $\left({ }^{\circ}\right)$ \\
\hline 1 & 10.43 & 56.56 & 33.01 & 16.69 \\
2 & 1.04 & 29.07 & 69.89 & 16.69 \\
3 & 28.11 & 30.00 & 41.89 & 8.53 \\
4 & 15.31 & 34.51 & 50.19 & 8.53 \\
\hline
\end{tabular}

\subsection{Prediction of Soil Loss by means of USLE}

First of all, the prediction of soil loss for soil samples of similar distribution of grain size by the USLE is discussed. Figure 2 shows the relationship between soil loss and R factor in each soil conditions. Furthermore, the experimental values and the calculation values by the USLE are showed as total soil loss. From these results, it can be said that soil sample 2 is matched with the experimental values and calculation values. On the other hand, these values are not corresponded with increasing of $\mathrm{R}$ factor in soil sample 1. Considering the differences of soil conditions, average grain size of soil sample 2 is smaller than soil sample 1 because almost $70 \%$ of soil sample consists of clay material. Therefore, it can be concluded that the applicability of the USLE for prediction of soil loss in the rehabilitation area depends on soil composition and rainfall intensity. In order to estimate and/or evaluate the soil loss by this equation with accuracy, some corrections including the effect of soil composition and climate condition has to be needed. 

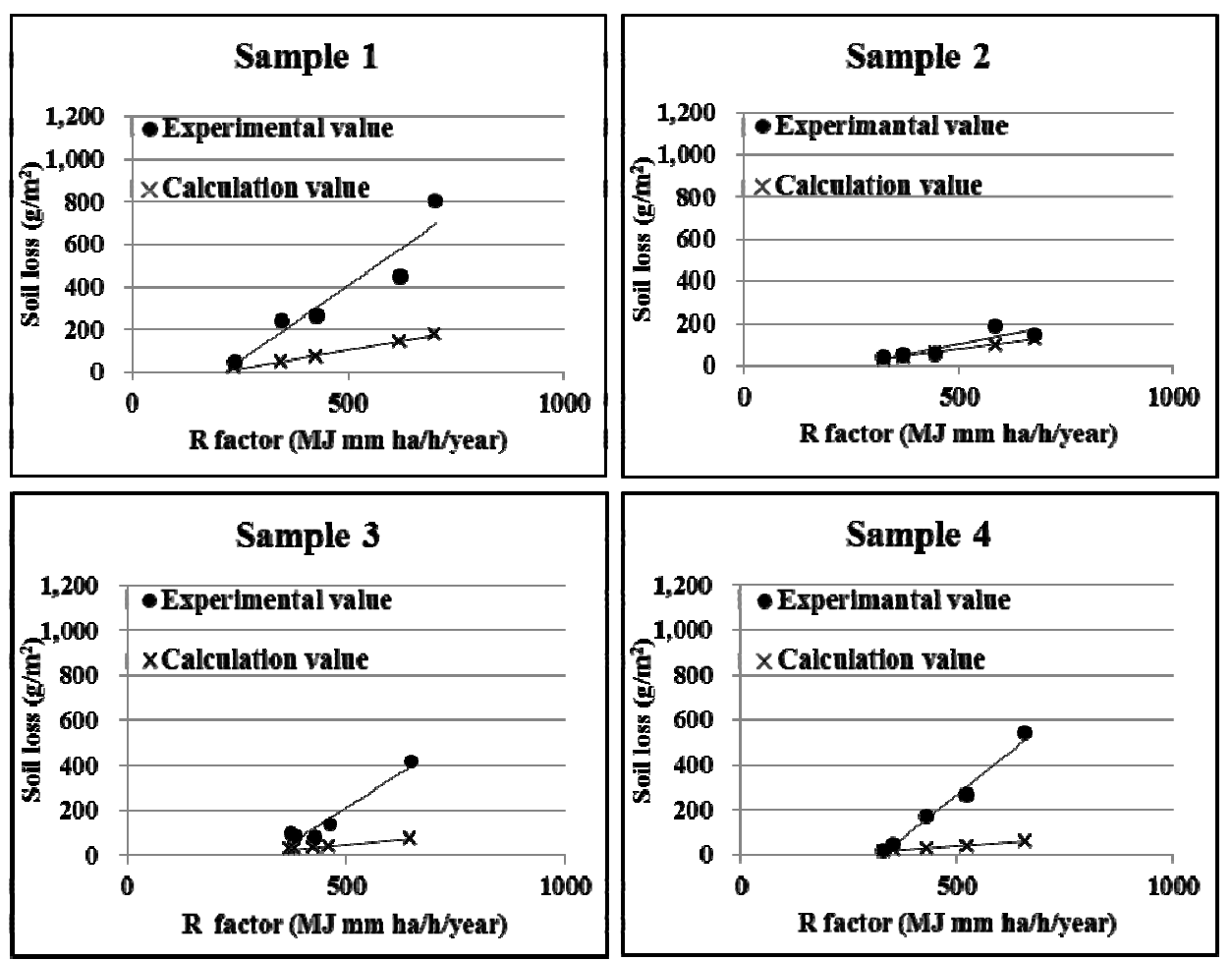

Figure 2. Comparison of experimental value and calculation value

\subsection{Characteristics of the Individual Soil}

In order to discuss the applicability of the USLE in the rehabilitation area in detail, the characteristics and the performance of soil loss on the individual soil were investigated. The state of consistency, called the Atterberg limits, is one of the strongly related parameter for soil loss as the erosion characteristics. Therefore, it can be said that this parameter can be used as the predictive value on soil loss. Figure 3 shows the distributed mechanism of soil by the different consistency limits.

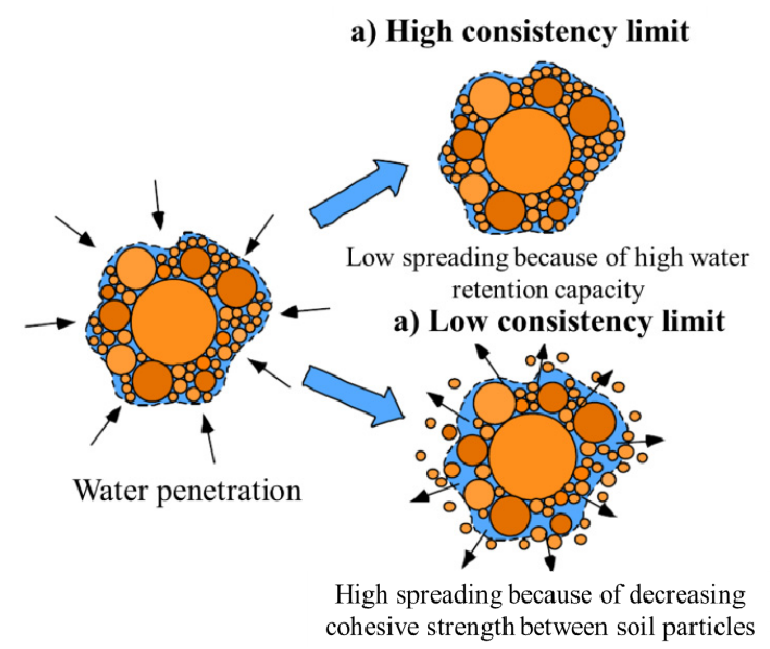

Figure 3. The distributed mechanism of soil

High consistency limit means that the cohesive strength between soil particles is high because soil has the high water retention capacity. On the other hand, its strength decreases because of occurrence of free water under the low consistency limit. Due to this, the risk of soil erosion decreases in the high consistency limit because of high cohesive strength as the reactive force for soil erosion (Taniguchi et al., 2011). 
The Atterberg limits test was conducted to determine the liquid and plastic limits (see Table 2) and the soil samples were classified by means of plasticity chart (see Figure 4). The consistency limits of clay shows high compared to that of sand and silt. Furthermore, clay was classified as $\mathrm{CH}$ whereas sand and silt were classified as ML. From these results, it can be expected that the soil erosion of sand and silt by rainfall is easy to occur due to low consistency limits. Moreover, soil particle density is rarely different by the soil type and shows approximately $2.6 \mathrm{~g} / \mathrm{cm}^{3}$. Therefore, once occurrence of soil erosion, the soil loss by rainfall may increase at an accelerated rate in sand and silt because these particle sizes are bigger than that of clay.

Table 2. Liquid and plastic limit in each soil

\begin{tabular}{cccc}
\hline Sample & Sand & Silt & Clay \\
\hline Soil density, $\rho_{s}\left(\mathrm{~g} / \mathrm{cm}^{3}\right)$ & 2.59 & 2.58 & 2.60 \\
Liquid limit, $w_{L}(\%)$ & 36.9 & 40.3 & 54.7 \\
Plastic Limit, $w_{P}(\%)$ & 25.2 & 27.7 & 28.5 \\
Plasticity Index, $I_{p}$ & 11.7 & 12.6 & 26.2 \\
Classification & ML & ML & CH \\
\hline
\end{tabular}

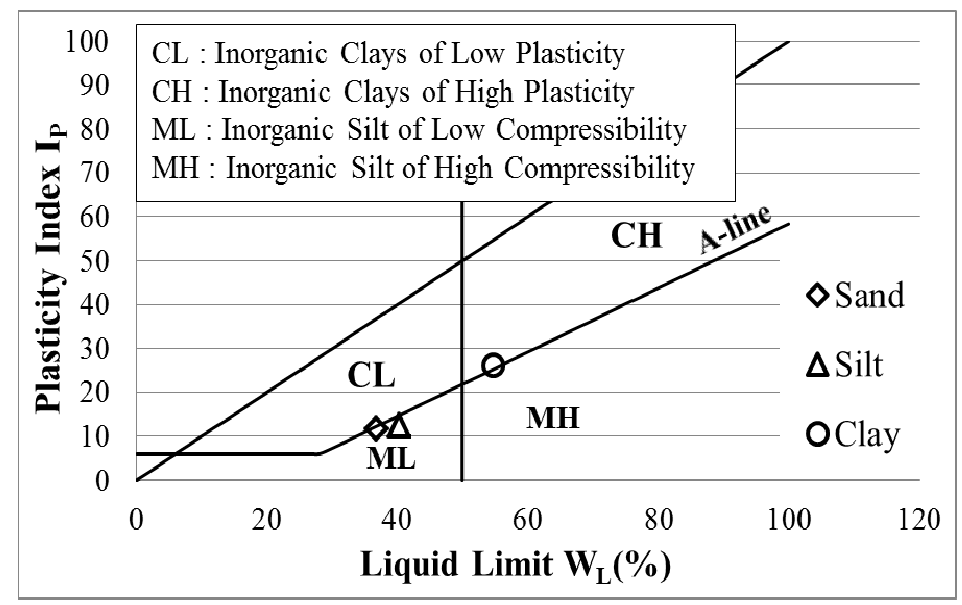

Figure 4. Plasticity chart

Figure 5 shows the results of artificial rainfall experiment on the individual soil. The slope angle was arranged to 15 degree. From these results, it can be said that the clay is matched with the experimental values and calculation values. By contrast, the soil loss of experimental value in the sand and silt exceeds dramatically than that of calculation value though these values are matched in the lower $\mathrm{R}$ factor. There is a clear correlation between consistency indices and the results of artificial rainfall experiment. Therefore, it can be said that soil characteristics related to soil erosion such as particle size and Atterberg limits are an important factor in order to predict soil loss in the rehabilitation area under the high rainfall intensity. 


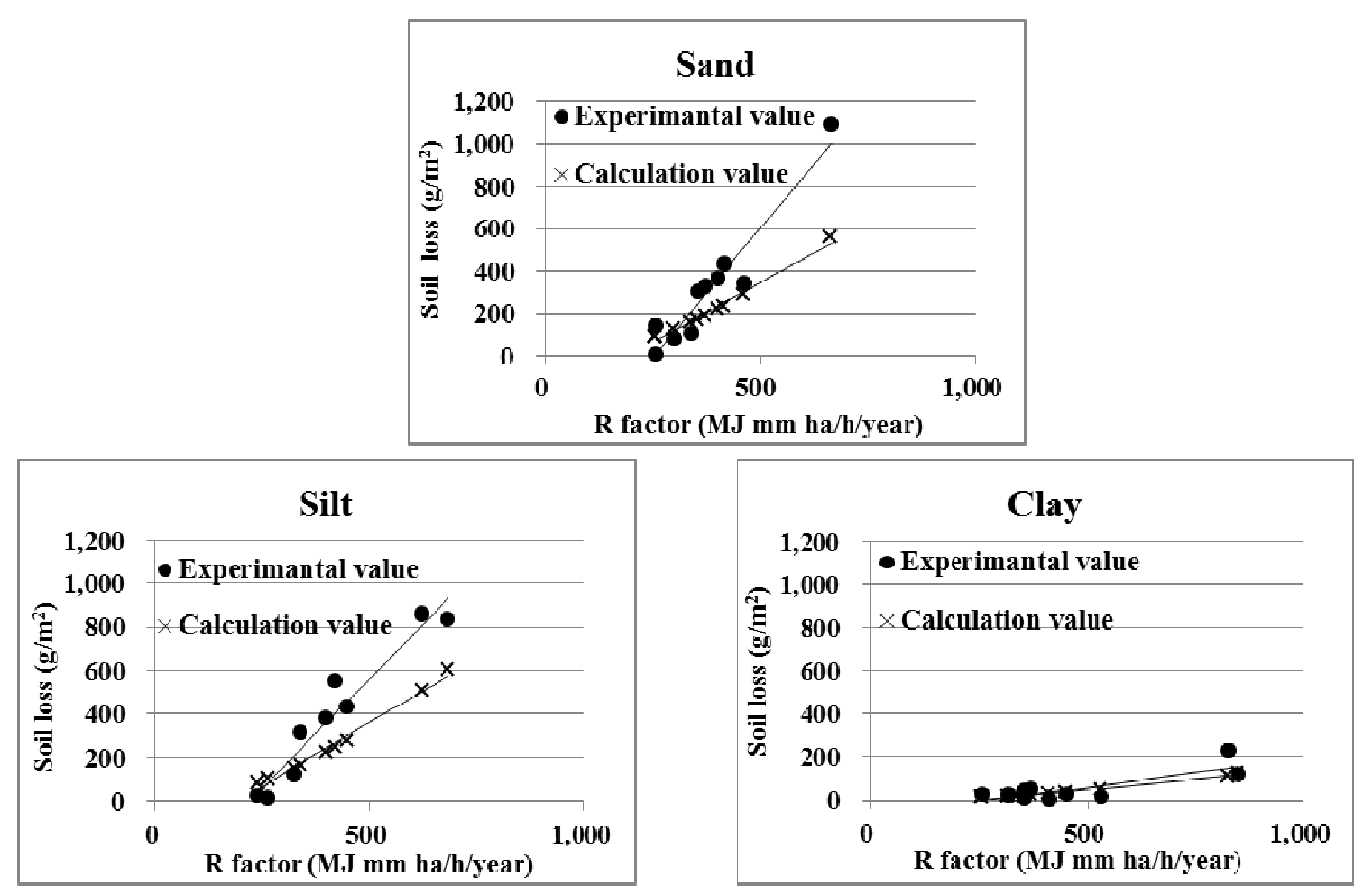

Figure 5. Comparison of experimental value and calculation value

\subsection{Several Considerations on Soil Erosion}

According to the results obtained in this study, USLE can apply the soil having a high erosion resistance, while soil loss of the soil with low consistency limits is difficult to be estimated by USLE under the high rainfall intensity. It can be considered that the excessive soil erosion such as rill erosion and surface erosion which is not available to predict by USLE occurred due to the cause of high tractive force by water flow generated between soil particles in the soil having a low consistency limit. From these reasons, it can be said that some corrections considering the condition in-situ such as soil component and climate condition have to be needed in order to predict the soil loss accurately by means of USLE.

Furthermore, it can be suspected that the risk of soil erosion is considerably increased in the rehabilitation area depending on soil characteristics since the excessive soil erosion is likely to occur under soil having a low consistency limit and a high rainfall intensity. In order to minimize the risk of erosion in rehabilitation area, adequate rehabilitation process to prevent soil erosion has to be considered such as selective placement of soil, establishment of erosion control structures, and planting rapid growing cover crop species immediately.

\section{Conclusion}

This paper described the present situation of soil erosion in Indonesian coal mine and discussed the applicability of USLE for predicting the soil loss under the rehabilitation area of Indonesian coal mine by the laboratory experiment. Consequently, the prediction of soil loss by the USLE becomes to be difficult with increasing the proportion of sand or silt in the soil though soil loss of experimental value and calculation value are accorded each other in the soil composed mostly of clay.

Consistency indices are useful and simple tools for the prediction of soil erosion. In the low consistency limits materials, it can be expected that excessive soil erosion is likely to occur due to high tractive force from free water between soil particles.

In order to predict the soil loss accurately by the USLE, the more discussion about some corrections considering the condition in-situ such as soil component and climate condition have to be needed. Additionally, immediate measure to minimize erosion risk has to be also considered since the risk of soil erosion is considerably increased in the rehabilitation area depending on soil characteristics. 


\section{Acknowledgments}

The first author wishes to extend their grateful thanks to PT Kaltim Prima Coal in Indonesia for the acceptance of visiting mine sites and cooperation in providing the samples and materials used in this study. Moreover, this research was conducted with financial support from associated cost of Grant-in-Aid for Scientific Research (JSPS KAKENHI Grant Number 24404025). The authors also wish to thank their financial supporting.

\section{References}

Commandeur, P. R. (1992). Soil erosion studies using rainfall simulation on forest harvested areas in British Colombia, Proceedings of the Chengdu Symposium, 21-28. Retrieved from http://www.for.gov.bc.ca/hfd/library/ffip/Commandeur_PR1992.pdf

Dimoyiannis, D. G., Valmis, S., \& Vyrlas, P. (2001). A RAINFALL SIMULATION STUDY OF EROSION OF SOME CALCAREOUS SOILS, Global Nest: The Int. J., 3(3), 179-183. Retrieved from http://journal.gnest.org/sites/default/files/Journal\%20Papers/dimoyiannis_179_184.pdf

Goldman, S. J., Jackson, K., \& Bursztynsky, T. A. (1986). Erosion and sediment control handbook, New York: McGraw-Hill.

Haan, C. T., Barfield, B. J., \& Hayes, J. C. (1994). Design Hydrology and Sedimentology for Small Catchments, New York: Academic Press, New York.

Hood, S. M., Zedaker, S. M., Aust, W. M., \& Smith, D. W. (2002). Universal Soil Loss Equation (USLE)-Predicted Soil Loss for Harvesting Regimes in Appalachian Hardwoods. NJAF, 19(2), 53-58. Retrieved from http://fishwild.vt.edu/faculty/haas_pdf/usle.pdf

Jha, V. C., \& Kapat, S. (2009). Rill and Gully Erosion Risk of Lateritic Terrain in South-Western Birbhum District, West Bengal, India. Soc. http://dx.doi.org/10.1590/S1982-45132009000200010

Taniguchi, Y., Komine, H., \& Murakami, S. (2011). Dominant Influence of Physico-Chemical Properties of Soil to Erosion Characteristics of Fine Grain Soil in River Levee and Bank, Proc. of 46th Japan National Conference on Geotechnical Engineering, 1051-1052.

Wischmeier, W. H., \& Smith, D. D. (1978). Predicting Rainfall Erosion Losses - A Guide to Conservation Planning, Washington, DC: U.S. Department of Agriculture.

\section{Copyrights}

Copyright for this article is retained by the author(s), with first publication rights granted to the journal.

This is an open-access article distributed under the terms and conditions of the Creative Commons Attribution license (http://creativecommons.org/licenses/by/3.0/). 